\title{
Long-Term Outpatient Care and Rehospitalizations in Patients after Cardiac Electrotherapy Device Implantation
}

\author{
Roman Załuska $^{1, *(D)}$, Anna Milewska ${ }^{2}\left(\mathbb{D}\right.$, Anastasius Moumtzoglou ${ }^{3}$, Marcin Grabowski ${ }^{4}(\mathbb{D}$ \\ and Wojciech Drygas ${ }^{5,6}$
}

check for

updates

Citation: Załuska, R.; Milewska, A.; Moumtzoglou, A.; Grabowski, M.; Drygas, W. Long-Term Outpatient Care and Rehospitalizations in Patients after Cardiac Electrotherapy Device Implantation. Medicina 2022, 58, 151. https://doi.org/10.3390/ medicina58020151

Academic Editor: Ignatios Ikonomidis

Received: 1 November 2021 Accepted: 17 January 2022

Published: 19 January 2022

Publisher's Note: MDPI stays neutral with regard to jurisdictional claims in published maps and institutional affiliations.

Copyright: (C) 2022 by the authors. Licensee MDPI, Basel, Switzerland. This article is an open access article distributed under the terms and conditions of the Creative Commons Attribution (CC BY) license (https:// creativecommons.org/licenses/by/ $4.0 /)$.
1 Department of Management and Logistics in Health Care, Medical University of Lodz, 90-131 Lodz, Poland 2 Department of Statistics and Medical Informatics, Medical University of Bialystok, 15-089 Bialystok, Poland; anna.milewska@umb.edu.pl

3 P. \& A. Kyriakou Children's Hospital, 11527 Athens, Greece; anastasius.moumtzoglou@gmail.com

4 1st Department of Cardiology, Medical University of Warsaw, 02-097 Warsaw, Poland; marcin.grabowski@wum.edu.pl

5 Department of Epidemiology, Cardiovascular Disease Prevention and Health Promotion, National Institute of Cardiology, 04-628 Warsaw, Poland; wdrygas@ikard.pl

6 Department of Social and Preventive Medicine, Medical University of Lodz, 90-419 Lodz, Poland

* Correspondence: roman.zaluska@stud.umed.lodz.pl; Tel.: +48-600-004-796

\begin{abstract}
Background and Objectives: Cardiovascular implantable electronic device (CIED) treatment is widely used in modern cardiology. Indications for this type of treatment are increasing. However, a significant proportion of CIED implantation patients require subsequent hospitalization for cardiovascular reasons. Older age and the associated complex clinical picture necessitate multidisciplinary outpatient specialist care for these patients. The aim of this study was to analyze the reasons for subsequent hospitalizations in the cardiology department and the impact of outpatient specialty care on these hospitalizations. To the best of our knowledge, there are no such studies in the available literature. Materials and Methods: This study was conducted on a population of patients treated with CIED. Reasons for subsequent hospitalizations were divided into clinically and statistically valid groups according to the main diagnosis. Using an electronic database, causes of hospitalization were determined based on this diagnosis. Using data on consultations at outpatient specialty clinics, a logistic regression model was created for the probability of subsequent hospitalization for cardiovascular causes according to the specialty of the clinic. Results: The 9-year follow-up included a population of 2071 patients treated with CIED. During the follow-up period, 508 patients (approximately 24.5\%) required subsequent hospitalization for cardiovascular reasons. The most common leading causes were heart failure, atrial fibrillation, and coronary artery disease. The need for consultation at outpatient specialty clinics increased the likelihood of hospitalization. Moreover, the need to consult patients in nephrology outpatient, pulmonary disease outpatient, and orthopedic outpatient clinics was the most significant. Conclusions: The use of electronic implantable cardiovascular devices is a very important part of therapy in modern cardiology. The methods for their use are constantly being improved. However, they represent only one stage of cardiac treatment. After CIED procedures, patients require further care in both inpatient and outpatient specialty care settings. In this paper, we outline the reasons for subsequent hospitalizations and the importance of outpatient specialty care in this context. Effective organization of care after CIED procedures may be important in reducing the most expensive component of this care, that is, inpatient treatment.
\end{abstract}

Keywords: cardiac electrotherapy devices; hospital readmissions; outpatient care

\section{Introduction}

Treatment with a cardiovascular implantable electronic device (CIED) is a very valuable method of management in modern cardiology. Indications for this therapy are constantly expanding. The latest guidelines from the European Society of Cardiology (ESC) 
concerning cardiac pacing and cardiac resynchronization therapy (CRT) were published in 2021 [1]. The indications for the use of implantable cardioverter defibrillators (ICDs) in heart failure were presented in the latest ESC guidelines, published in August of 2021 [2]. Data on the use of ICD in the prevention of sudden cardiac death and ventricular arrhythmias are somewhat older $[3,4]$. The population of patients treated with these methods is becoming older and thus more burdened with comorbidities. Despite modern treatment methods, the prognosis of these patients remains serious. This is especially true for patients with implanted single-chamber pacing systems and after generator replacement, as we demonstrated in an earlier paper [5]. The implantation of the device also has a very important diagnostic function. Modern systems allow for the diagnosis of subclinical atrial fibrillation. One review found that approximately one-third of patients with risk factors for stroke but without atrial fibrillation at the time of implantation were diagnosed with paroxysmal subclinical atrial fibrillation within 3 years. This is of considerable clinical significance [6]. System implantation is only one step in the treatment of these patients. The complexity of the clinical picture is one of the reasons for subsequent hospitalizations for cardiac reasons. These patients also require specialist outpatient treatment in various outpatient clinics. The purpose of this study was to describe the reasons for subsequent cardiac hospitalizations in this population and the impact of the need for outpatient specialty care on these hospitalizations.

\section{Materials and Methods}

\subsection{Study Population}

The present single-center analysis was carried out based on data acquired from the Electrophysiology Laboratory of the Masovian Specialist Hospital in Ostroleka, where approximately 300 procedures of this type are performed annually. Over the course of nine years (2010-2018), the analysis considered a large group of patients with a history of implantation of single- and double-chamber pacemaker devices, cardioverter defibrillators, and cardiac resynchronization devices.

Using an electronic database and hospital treatment information sheets, data were collected on subsequent hospitalizations after discharge following device implantation. The data on reasons for rehospitalization based on main diagnosis come from the database we created for the study population.

Hospital treatment information sheets included the main reason for hospitalization and comorbid diagnoses. Reasons for subsequent hospitalizations were divided into clinically and statistically valid groups according to the main diagnosis (Group 1: heart failure (HF); Group 2: atrial fibrillation (AF); Group 3: coronary artery disease (CAD); Group 4: other cardiac arrhythmias; Group 5: infective endocarditis; Group 6: other causes). A multivariate logistic regression model including data on outpatient specialist consultations, certain clinical data, age, and length of hospitalization associated with device implantation was used to estimate the chances of another cardiac hospitalization.

\subsection{Statistical Analysis}

In the statistical analysis, the chi-square independence test was used to check the relationship between quality characteristics. The normality of distribution was verified using Kolmogorov-Smirnov tests, with Lillefors correction and the Shapiro-Wilk test. A nonparametric Kruskal-Wallis one-way ANOVA on ranks test with a post-hoc test of multiple comparisons of mean ranges for all samples was used to compare quantitative variables without normality of distribution in the case of many groups. Survival curves were estimated using the Kaplan-Meier method. Differences between survival curves were assessed using the log-rank test. Statistically significant results were considered at $p<0.05$. In order to carry out the calculations, Statistica 13.3 (Statsoft Inc. Tulsa, OK, USA) and Stata/IC 13 (StataCorp, College Station, TX, USA) were used. 


\section{Results}

A population of 2071 patients undergoing cardiac electrotherapy device implantation was analyzed regarding rehospitalization for cardiac reasons. A total of 508 patients required at least one hospitalization. This population was slightly younger and predominantly male. Patients with implanted ICD/CRT systems required rehospitalization more frequently. Among the comorbidities, atrial fibrillation, chronic obstructive pulmonary disease (COPD), and coronary artery disease were significantly more frequent. The characteristics of the group requiring hospitalization as compared with those not requiring further hospital treatment at the cardiology department are shown in Table 1. Table 2 shows the primary indications for device implantation.

The long-term survival of rehospitalized and non-rehospitalized patients (days; median) was not significantly different (2966 vs. 2965). The survival curves of patients who were rehospitalized and those not requiring further hospitalization after device implantation are shown in Figure 1.

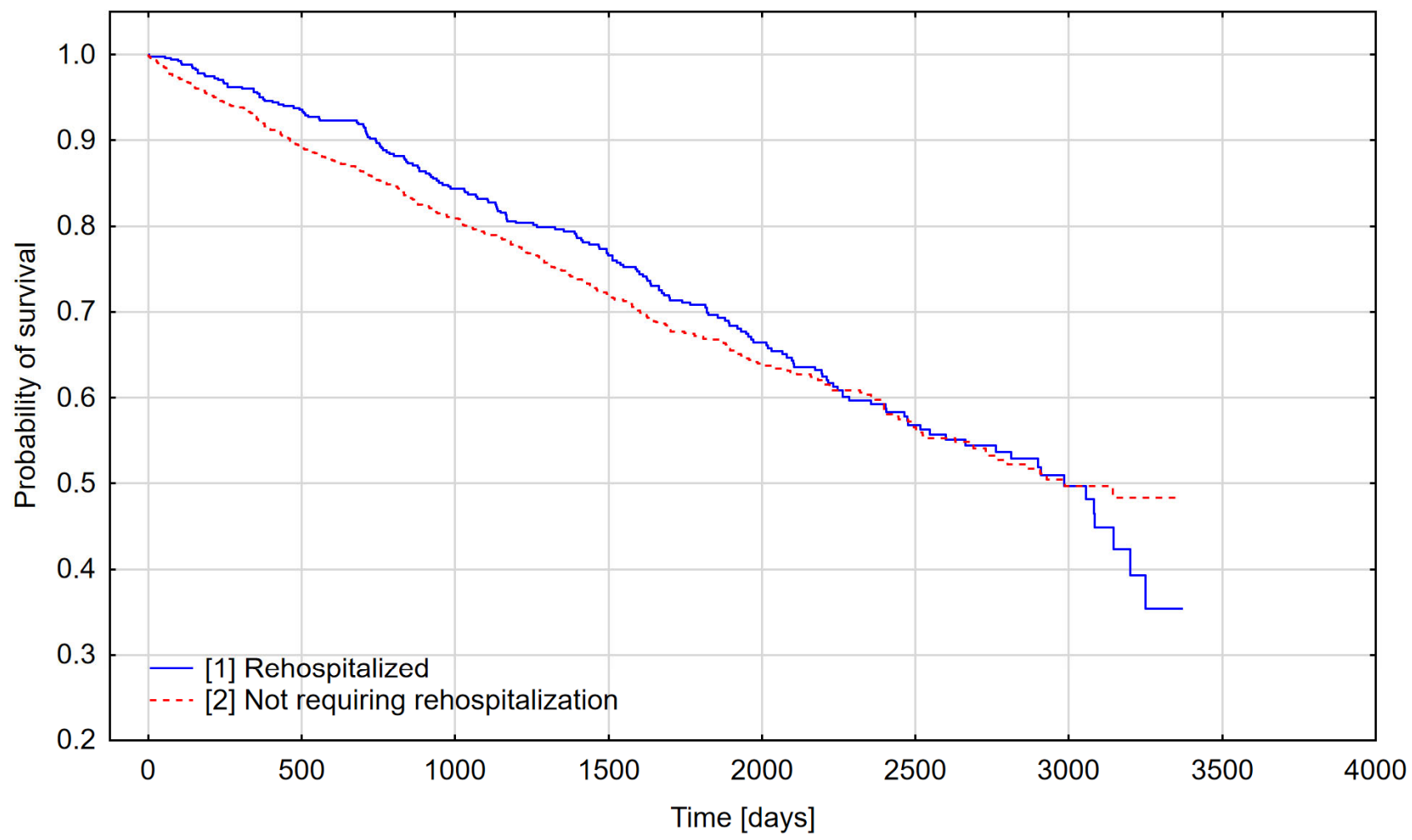

Number at risk

$\begin{array}{llrrrrrr}\text { Time } 0 & 500 & 1000 & 1500 & 2000 & 2500 & 3000 \\ {[1]} & 560 & 1135 & 809 & 542 & 321 & 176 & 65 \\ {[2]} & 508 & 449 & 367 & 292 & 195 & 106 & 38\end{array}$

Figure 1. Kaplan-Meier curves showing the survival of rehospitalized and non-requiring rehospitalization patients following cardiovascular implantable electronic device implantation $(p=0.392)$.

The main diagnoses during readmissions in the study group $(n=508)$ were as follows: $\mathrm{HF}(n=301 ; 59 \%)$; $\mathrm{AF}(n=87 ; 17 \%)$ CAD $(n=43 ; 9 \%)$; other arrhythmias $(n=37 ; 7 \%)$; infective endocarditis $(n=9 ; 2 \%)$; other causes $(n=31 ; 6 \%)$;

Survival of patients depending on the main cause of subsequent hospitalization is shown in Figure 2. 


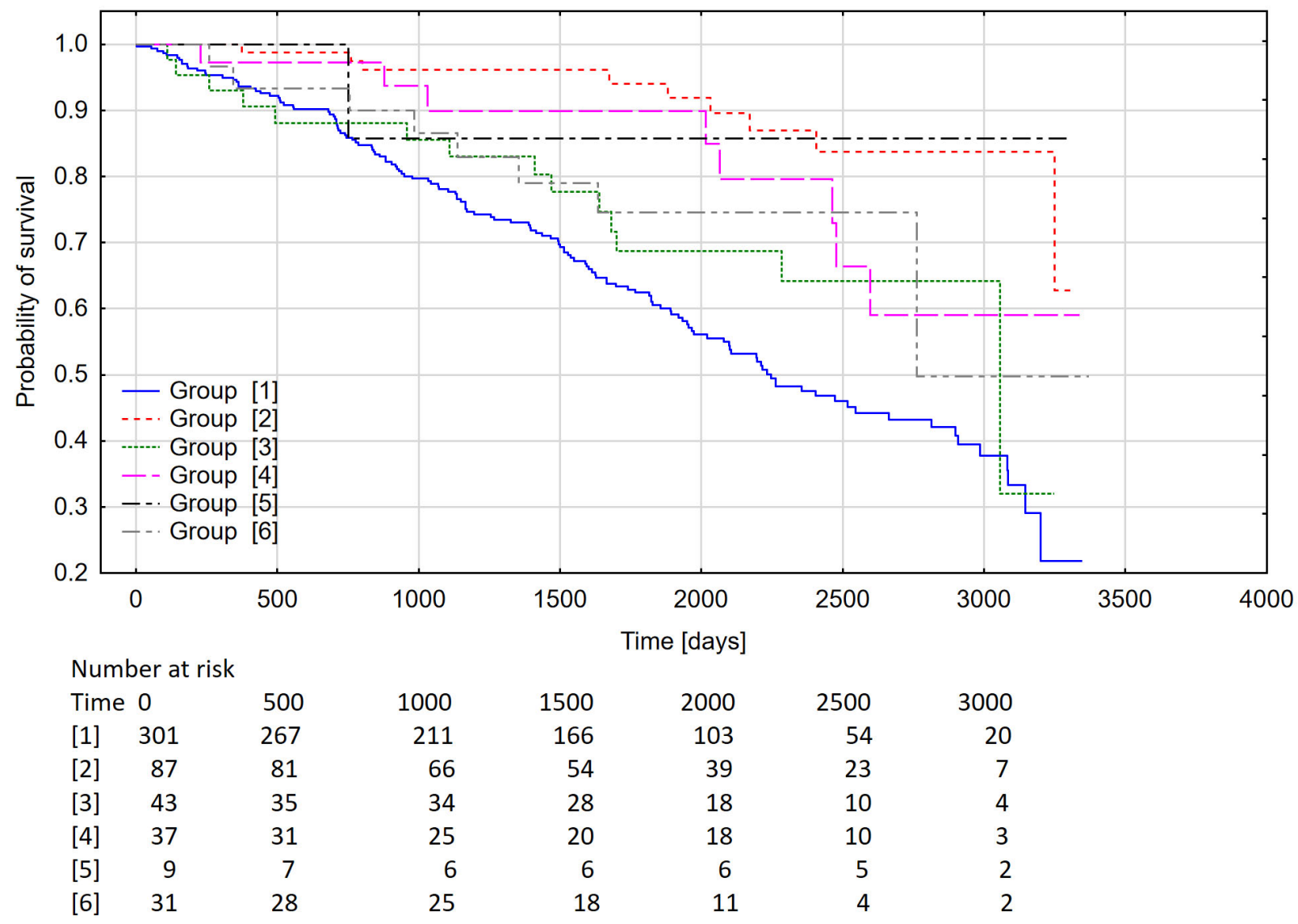

Figure 2. Kaplan-Meier curve representing the probability of survival for the groups of diagnoses $(p<0.001)$. Group 1: heart failure; Group 2: atrial fibrillation; Group 3: coronary artery disease; Group 4: other cardiac arrhythmias; Group 5: infective endocarditis; Group 6: other cases.

During the study period, patients requiring rehospitalization had 408 consultations at a cardiology outpatient clinic, 91 at a urology outpatient clinic, 89 at an orthopedic outpatient clinic, 80 at an ophthalmologic outpatient clinic, 79 at a vascular surgery outpatient clinic, 74 at a general surgery outpatient clinic, 61 at a lung disease outpatient clinic, and 57 at a nephrology outpatient clinic.

A multivariate logistic regression model assessing the chance of subsequent rehospitalization after CIED implantation (taking into account the need for a specialist outpatient clinic consultation, certain clinical data, age at implantation, and length of implant-related hospitalization) is presented in Table 3. On the basis of the analysis performed, it was found that diseases requiring specialist nephrological, pulmonological, and orthopedic treatment had the greatest impact on the necessity of readmission to hospital for the above reasons.

Table 1. The characteristics of groups of patients rehospitalized versus those not requiring rehospitalization following CIED implantation (data presented as numbers and percentages).

\begin{tabular}{cccc}
\hline Variable & $\begin{array}{c}\text { Rehospitalized Patients } \\
\boldsymbol{n}=\mathbf{5 0 8}\end{array}$ & $\begin{array}{c}\text { Patients Not Requiring } \\
\text { Rehospitalization } \\
\boldsymbol{n}=\mathbf{1 5 6 3}\end{array}$ & $\boldsymbol{p}$-Value \\
\hline \multirow{2}{*}{ Age (years) } & $\begin{array}{c}76.0 \\
(68.0-82.0)\end{array}$ & $(70.0-83.0)$ & $<0.001 *$ \\
\hline Male & 283 & 794 & 0.054 \\
\hline
\end{tabular}


Table 1. Cont.

\begin{tabular}{|c|c|c|c|}
\hline Variable & $\begin{array}{l}\text { Rehospitalized Patients } \\
\qquad n=508\end{array}$ & $\begin{array}{c}\text { Patients Not Requiring } \\
\text { Rehospitalization } \\
n=1563\end{array}$ & $p$-Value \\
\hline SC-AAI/VVI & $\begin{array}{c}160 \\
(31.5 \%)\end{array}$ & $\begin{array}{c}530 \\
(33.9 \%)\end{array}$ & \multirow{3}{*}{$<0.001 *$} \\
\hline DC-DDD & $\begin{array}{c}251 \\
(49.4 \%)\end{array}$ & $\begin{array}{c}856 \\
(54.8 \%)\end{array}$ & \\
\hline $\mathrm{ICD} / \mathrm{CRT}$ & $\begin{array}{c}97 \\
(19.1 \%)\end{array}$ & $\begin{array}{c}177 \\
(11.3 \%)\end{array}$ & \\
\hline Heart failure II NYHA class & $\begin{array}{c}146 \\
(28.7 \%)\end{array}$ & $\begin{array}{c}412 \\
(26.4 \%)\end{array}$ & 0.293 \\
\hline Heart failure III NYHA class & $\begin{array}{c}98 \\
(19.3 \%)\end{array}$ & $\begin{array}{c}178 \\
(11.4 \%)\end{array}$ & $<0.001$ * \\
\hline Hypertension & $\begin{array}{c}325 \\
(64.0 \%)\end{array}$ & $\begin{array}{c}1119 \\
(71.6 \%)\end{array}$ & $0.001 *$ \\
\hline Diabetes & $\begin{array}{c}155 \\
(30.5 \%)\end{array}$ & $\begin{array}{c}440 \\
(28.2 \%)\end{array}$ & 0.307 \\
\hline Coronary artery disease & $\begin{array}{c}209 \\
(41.1 \%)\end{array}$ & $\begin{array}{c}579 \\
(37.0 \%)\end{array}$ & 0.098 \\
\hline Dilated cardiomyopathy & $\begin{array}{c}27 \\
(5.3 \%)\end{array}$ & $\begin{array}{c}40 \\
(2.6 \%)\end{array}$ & $0.002 *$ \\
\hline Hypertrophic cardiomyopathy & $\begin{array}{c}2 \\
(0.4 \%)\end{array}$ & $\begin{array}{c}3 \\
(0.2 \%)\end{array}$ & - \\
\hline Atrial fibrillation & $\begin{array}{c}177 \\
(38.4 \%)\end{array}$ & $\begin{array}{c}393 \\
(25.1 \%)\end{array}$ & $<0.001$ * \\
\hline History of stroke & $\begin{array}{c}55 \\
(10.8 \%)\end{array}$ & $\begin{array}{c}160 \\
(10.2 \%)\end{array}$ & 0.705 \\
\hline $\begin{array}{l}\text { Chronic obstructive pulmonary disease } \\
\text { (COPD) }\end{array}$ & $\begin{array}{c}61 \\
(12.0 \%)\end{array}$ & $\begin{array}{c}100 \\
(6.4 \%)\end{array}$ & $<0.001$ * \\
\hline Chronic kidney disease (CKD) & $\begin{array}{c}76 \\
(15.0 \%)\end{array}$ & $\begin{array}{c}249 \\
(15.9 \%)\end{array}$ & 0.601 \\
\hline Hyperthyroidism & $\begin{array}{c}22 \\
(4.3 \%)\end{array}$ & $\begin{array}{c}55 \\
(3.5 \%)\end{array}$ & 0.401 \\
\hline Hypothyroidism & $\begin{array}{c}26 \\
(5.1 \%)\end{array}$ & $\begin{array}{c}78 \\
(5.0 \%)\end{array}$ & 0.909 \\
\hline LVEF_-primary prevention & $\begin{array}{c}29.0 \% \\
(25.0-33.0)\end{array}$ & $\begin{array}{c}30 \% \\
(25.0-33.0)\end{array}$ & 0.652 \\
\hline LVEF—secondary prevention & $\begin{array}{c}37.0 \% \\
(30.0-45.0)\end{array}$ & $\begin{array}{c}39.0 \% \\
(30.0-45.0)\end{array}$ & 0.570 \\
\hline Type of procedure & $n$ & $n$ & \\
\hline First time implantation & $\begin{array}{c}471 \\
(92.7 \%)\end{array}$ & $\begin{array}{c}1461 \\
(93.5 \%)\end{array}$ & 0.553 \\
\hline
\end{tabular}

* The differences are statistically significant at $p<0.05$. CIED, cardiovascular implantable electronic device; SC, single chamber; DC, dual chamber; AAI, atrial single-chamber pacemaker; VVI, ventricular single-chamber pacemaker; DDD, dual-chamber pacemaker; ICD, implantable cardioverter defibrillator; CRT, cardiac resynchronization therapy; NYHA, New York Heart Association; LVEF, left ventricular ejection fraction; AV, atrioventricular. 
Table 2. Primary indications for device implantation (data presented as numbers and percentages).

\begin{tabular}{|c|c|c|c|}
\hline Primary Indications & $\begin{array}{l}\text { Rehospitalized Patients } \\
\qquad n=508\end{array}$ & $\begin{array}{l}\text { Patients Not Requiring } \\
\text { Rehospitalization } \\
n=1563\end{array}$ & $p$-Value \\
\hline Atrial fibrillation with AV block & $\begin{array}{c}141 \\
(27.8 \%)\end{array}$ & $\begin{array}{c}393 \\
(25.1 \%)\end{array}$ & 0.242 \\
\hline AV block III & $\begin{array}{c}54 \\
(10.6 \%)\end{array}$ & $\begin{array}{c}349 \\
(22.3 \%)\end{array}$ & $<0.001 *$ \\
\hline Sick sinus syndrome & $\begin{array}{c}151 \\
(29.7 \%)\end{array}$ & $\begin{array}{c}434 \\
(27.8 \%)\end{array}$ & 0.395 \\
\hline AV block II t.2 & $\begin{array}{c}43 \\
(8.5 \%)\end{array}$ & $\begin{array}{c}110 \\
(7.0 \%)\end{array}$ & 0.285 \\
\hline AV block 2:1 & $\begin{array}{c}18 \\
(3.5 \%)\end{array}$ & $\begin{array}{c}94 \\
(6.0 \%)\end{array}$ & $0.032 *$ \\
\hline Trifascicular block & $\begin{array}{c}1 \\
(0.2 \%)\end{array}$ & $\begin{array}{c}1 \\
(0.06 \%)\end{array}$ & - \\
\hline AV block II t.1 & $\begin{array}{c}8 \\
(1.6 \%)\end{array}$ & $\begin{array}{c}12 \\
(0.8 \%)\end{array}$ & 0.106 \\
\hline Alternating bundle branch block & - & $\begin{array}{c}2 \\
(0.1 \%)\end{array}$ & - \\
\hline Cardiac arrest—primary prevention & $\begin{array}{c}74 \\
(14.6 \%)\end{array}$ & $\begin{array}{c}131 \\
(8.4 \%)\end{array}$ & $<0.001 *$ \\
\hline Cardiac arrest-secondary prevention & $\begin{array}{c}23 \\
(4.5 \%)\end{array}$ & $\begin{array}{c}46 \\
(2.9 \%)\end{array}$ & 0.084 \\
\hline
\end{tabular}

* The differences are statistically significant at $p<0.05 . \mathrm{AV}$, atrioventricular.

Table 3. Multivariate logistic regression model estimating the chances of rehospitalization following CIED implantation.

\begin{tabular}{cccc}
\hline Consultations in Specialist Clinics & OR & $\mathbf{9 5 \%}$ CI & $p$-Value \\
\hline Nephrology outpatient clinic & 3.74 & $2.35-5.95$ & $<0.001^{*}$ \\
Lung disease outpatient clinic & 2.17 & $1.42-3.31$ & $<0.001^{*}$ \\
Orthopedic outpatient clinic & 2.02 & $1.42-2.87$ & $<0.001^{*}$ \\
Vascular surgery outpatient clinic & 1.77 & $1.23-2.57$ & $0.002^{*}$ \\
General surgery outpatient clinic & 1.72 & $1.18-2.50$ & $0.005^{*}$ \\
Ophthalmological outpatient clinic & 1.57 & $1.09-2.26$ & $0.015^{*}$ \\
Urology outpatient clinic & 1.43 & $1.02-2.02$ & $0.039^{*}$ \\
Cardiology outpatient clinic & 1.30 & $1.01-1.68$ & $0.043^{*}$ \\
$\quad$ Clinical data & & & \\
Chronic obstructive pulmonary disease & 1.76 & $1.25-2.50$ & $0.001^{*}$ \\
Heart failure III NYHA class & 1.59 & $1.20-2.12$ & $0.001^{*}$ \\
AV block 2:1 & 0.55 & $0.33-0.93$ & $0.024^{*}$ \\
AV block III & 0.43 & $0.31-0.59$ & $<0.001 *$ \\
Other factors & & & \\
Length of hospitalization & 1.04 & $1.03-1.06$ & $<0.001 *$ \\
Age & 0.99 & $0.98-1.00$ & $0.012^{*}$
\end{tabular}

* The differences are statistically significant at $p<0.05$. OR, odds ratio; CI, confidence interval; NYHA, New York Heart Association; AV, atrioventricular.

\section{Discussion}

\subsection{Most Common Causes of Rehospitalizations for Cardiovascular Causes}

The problem of rehospitalizations affects all healthcare systems, and is an important factor in increasing the overall cost of treatment. The excessive number of hospitalizations and the focus on expensive hospital care upsets the balance between the inpatient and outpatient sectors. Cardiovascular diseases are the most common causes of hospitalization 
in Poland, at a rate of 13\%. Men are twice as likely to be hospitalized for diseases related to atherosclerosis, and only slightly less frequently for cardiovascular diseases, chronic kidney disease, liver diseases, and injuries. The share of cardiovascular diseases increases as the population ages. These ratios have increased by $25 \%$ in recent years. The incidence of hospitalization in Poland is similar to that in other EU countries. In recent years, there has been an increase of $30 \%$ [7].

In this study, we analyzed the cardiovascular causes of the rehospitalization of patients after CIED treatment. In the medical literature, there is a shortage of studies on the problem of rehospitalization for cardiac reasons in patients with implanted devices for heart electrotherapy. The available studies include only short- and mid-term analyses of rehospitalizations following high-energy device (ICD, CRTD) implantations. As in the present paper, the most common cause of hospitalization was heart failure [8]. Patients with ischemic heart disease were at higher risk of further hospitalization [9].

Hospitalizations due to HF account for 1-2\% of all hospital admissions [10]. Approximately half of patients are admitted at least once a year after diagnosis, and this figure increases to approximately $80 \%$ within 5 years $[11,12]$. As a result of the ageing of the population, this percentage is projected to increase steadily over the coming years. A six-month analysis of the reasons for rehospitalization of patients with heart failure by Umehara et al. showed that CKD, dementia, and low motor performance were risk factors for rehospitalization [13].

Heart failure represents a new 21st century epidemic. The most common cause is ischemic heart disease (70\%). The number of patients with heart failure in Poland exceeds 750,000 , and forecasts predict an increase of about $25 \%$ within a decade [14].

This disease is the most common cause of hospitalization in patients above 65 years of age in Poland. The median age of the study population was 76 years. For this reason, hospitalization rates are among the highest in Europe (twice as those in OECD countries; five times higher than those in the UK) [15].

The most common cause of rehospitalization was heart failure; however, in Table 3 , it is shown that COPD had a higher OR than HF in causing rehospitalization. Table 3 includes some of the clinical data including comorbidities with which patients in the study population were burdened during hospitalization related to implantation of a cardiac electrotherapy device. Reasons for rehospitalization were determined based on the principal diagnosis (data were derived from hospital treatment information sheets). Being under the care of an outpatient lung disease clinic significantly increased the chance of rehospitalization for cardiac reasons. Among these patients, many were burdened with COPD. Hospitalization costs account for more than $90 \%$ of the system's expenditure on the treatment of heart failure. Five-year survival is comparable or worse than that for most cancers. The coordination of post-hospital care may involve a reduction in the number of heart failure hospitalizations by approximately $34 \%$, and the total number of hospitalizations by approximately $27 \%$ [16].

In the present 9 -year analysis, more than $38 \%$ of patients experienced atrial fibrillation. AF was the second most common cause of rehospitalization after this kind of treatment. The available literature lacks data on the prevalence of AF in the population with implanted electrotherapy devices and the need for rehospitalization for this reason.

Medical progress has improved the quality of life of these patients, but there is an observable increase in the frequency of hospitalizations for this reason. This generates increasing treatment costs $[17,18]$. A total of $15-18 \%$ of patients require rehospitalization within 30 days of discharge $[17,19]$. Atrial fibrillation is one of the most common arrhythmias. As a result of the ageing of the population, its frequency is increasing. The prevalence of this disease is underestimated due to its mild or asymptomatic course in many patients. This arrhythmia is of very high public health significance because of the significant impact on mortality due to ischemic stroke, heart failure, and acute coronary syndromes [6,20].

The most common causes of readmissions presented in the present study are pathophysiologically related. Atrial fibrillation, coexisting with hypertension, metabolic syndrome, dyslipidemia, and diabetes, accelerates the development of atherosclerosis. Heart 
attack is a fairly typical element of the natural history of atrial fibrillation. Ischemic injury is the most common cause of heart failure. A large proportion of patients with heart failure suffer from atrial fibrillation.

\subsection{Rehospitalizations for Cardiovascular Causes-The Impact of Outpatient Specialty Care}

The present study also analyzed the impact of specialist outpatient care on hospitalizations for cardiac reasons. Studies of this type have not been published until now. The population of 508 patients was consulted in various specialist outpatient clinics during the follow-up period. In total, 939 consultations were held in the clinics of our hospital. We showed that patients under the care of certain specialty clinics were more likely to have subsequent hospitalizations for cardiovascular causes. This may be due to the fact that comorbidities that increase the chances of hospitalization are within the focus of these outpatient clinics, but may also reflect inefficient organization of the health care system. In rural areas, access to specialty care is worse than in urban areas. The need for hospitalization may have resulted from a lack of coordination between different sectors of medical care. The study group had a predominantly elderly population. These patients were burdened with various comorbidities. A total of $15 \%$ of those rehospitalized for cardiovascular reasons had chronic kidney disease. CKD affects approximately $10 \%$ of the adult population and is associated with increased morbidity and mortality. There were also high rates of hospitalization in this group [21-24]. One in four patients with CKD was hospitalized due to heart failure [25]. In our study, we showed that CKD, as the most common reason for needing care in an outpatient nephrology clinic, had an impact on hospitalizations for cardiovascular causes. This result is caused by the fact that our analysis was retrospective and confirms influence of concomitant diseases on patient prognosis including hospitalizations. CKD remains, also in populations of patients with cardiac implantable devices, one of the strongest factors negatively influencing health status independently. According to the created model, an increased chance of hospitalization for cardiological reasons was shown for several clinics (nephrology, lung diseases, orthopedic, vascular surgery, general surgery, ophthalmology, urology, and cardiology). The greatest chance of hospitalization occurred in the population of patients consulted in the nephrological dispensary and lung disease outpatient clinic.

Older age, multiple morbidity, and a lack of coordination of specialist care may explain the significant increase in the chance of further hospitalization.

In recent years, the lack of coordination in ambulatory specialist care and the associated negative consequences in the form of poor clinical outcomes have come to light. This also causes low patient acceptance [26-31]. The coexistence of comorbidities, typical of ageing societies, exacerbates the effects of the lack of coordination of care and increases the incidence of hospitalization. In the older population, multiple morbidity is common-it is estimated at $50-85 \%$ [32,33].

While ambulatory specialist care is not optimally coordinated, there is also a lack of proper communication between outpatient specialist care and primary care. This can be attributed to various factors, including a lack of regulation, as well as a lack of integration of information systems in these healthcare sectors. In a study by Kailasam et al., the greatest fragmentation was found in hematology, endocrinology, and anesthesia clinics [34]. The lack of coordination of specialist care may lead to further hospitalizations.

\subsection{Rehospitalizations for Cardiovascular Causes - The Importance of Some Comorbidities}

Among comorbidities, COPD and the HF III NYHA class were shown to be the most significant in increasing the odds of hospitalization for cardiovascular reasons. In the present study, the rate of heart failure among patients with COPD was $70.5 \%$, and the rate of COPD in patients with HF was $17.6 \%$. This was less common in patients who did not require further hospitalization. Patients controlled at the Lung Disease Clinic were more than twice as likely to be hospitalized for cardiac reasons. Among patients requiring rehospitalization, the proportion of patients burdened with COPD was higher 
than the average for Poland and amounted to $12 \%$ (not requiring hospitalization: $6.4 \%$ ). The incidence of heart failure in patients with COPD ranges from $10 \%$ to $46 \%$ [35], and the incidence of COPD in patients with HF is approximately $10-20 \%$. This proportion increases in older age groups $[36,37]$. The greatest risk of rehospitalization is associated with the coexistence of chronic obstructive pulmonary disease with chronic heart failure and osteoporosis [38]. COPD is one of the most common chronic diseases (7.6\%), and represents an increasing economic burden on healthcare systems [39,40]. In the Polish population, the prevalence of COPD among patients above 40 years of age is larger, and amounts to about $10 \%$. The risk of developing heart failure among COPD patients is almost five times higher than that in the general population [41]. In the work Kaszuba et al., it was shown that if $\mathrm{HF}$ and COPD occur at the same time, other cardiovascular diseases aggravating the prognosis of these patients are more often observed [42]. During an exacerbation of COPD, new or worsening cardiac arrhythmias (e.g., atrial fibrillation) occur. This is sometimes an indication for hospital treatment for cardiological reasons. As the respiratory function of the lungs deteriorates due to the development of pulmonary hypertension, right ventricular heart failure develops.

\subsection{Survival of Patients According to Rehospitalization and Those Not Requiring Hospitalization}

The statistically insignificant lack of difference in survival between patients requiring rehospitalization for cardiac reasons and those not requiring rehospitalization, obtained in the present study, may have been due to the specificity of the health care system in an area with predominantly rural areas. Due to difficult access to outpatient specialist care, the cardiology department had to take over some of the functions of outpatient specialist care. Patients were admitted to hospital more often but in less advanced stages of the disease. This could have a positive prognostic significance. In an analysis evaluating access to medical services in rural areas, it was found that hospitalization rates increase according to the rurality of the area in which patients reside. The average length of hospitalization decreases. A higher percentage of patients receives care in hospitals, among others, in Hospital Emergency Departments and primary care clinics. This adversely affects the health status of this population [43]. In the available literature, the prognosis of patients requiring hospitalization is worse regardless of the severity of heart failure [12].

\subsection{Survival of Patients Depending on the Main Cause of Subsequent Hospitalization}

We analyzed the survival of patients according to the criteria used in the analysis of the frequency of rehospitalizations. As expected, the group with heart failure as the main diagnosis was burdened with the worst prognosis, later, in contrast to that analysis, were coronary artery disease and atrial fibrillation as main diagnoses.

There are few long-term studies of this type in the available literature. The 3-year study by Lamblin et al. was conducted on a younger population than in our analysis. A total of $70.6 \%$ of patients had only one disease burden at the time of inclusion in the analysis. Mortality was highest for HF (27\%). Mortality rates for atrial fibrillation and coronary artery disease were $17.5 \%$ and $12.2 \%$, respectively [44].

Almost half of the patients in the group analyzed were burdened with heart failure already before implantation of CIED and over $41 \%$ with coronary artery disease, and atrial fibrillation was present in almost $40 \%$ of patients. Other relevant factors were hypertension $(2 / 3$ of patients) and diabetes (almost $1 / 3$ of patients). Prevalence of these concomitant diseases is higher than in the general population.

The prevalence of heart failure is increasing in ageing populations [45,46]. Over the age of 70 , the prevalence is about $10 \%[47,48]$. The prognosis is still poor despite continuous improvement associated with the introduction of modern methods of treatment according to constantly updated guidelines. The prognosis is worse in observational studies than in clinical trials. A study combining the Framingham Heart Study and Cardiovascular Health Study Cohort reported a $67 \%$ mortality rate within 5 years of diagnosis [49]. 
Coronary artery disease is one of the leading reasons for the prevalence and mortality in the older population. There are few papers in the available literature that analyze the diagnosis, management, and course of CAD in older age groups. Older patients are often excluded from clinical trials [50]. CAD's dissemination grows with the age of patients, constituting $10-12 \%$ in women aged $65-84$ and $12-14 \%$ in men of the same age. The yearly mortality depends on the complexity of the clinical picture. In case of numerous burdens, peripheral arterial disease, history of heart failure and diabetes, it is about 3.8\% [51].

Like in the case of $\mathrm{HF}$ or $\mathrm{CAD}$, the incidence of atrial fibrillation is constantly increasing. It is estimated that the incidence of atrial fibrillation in adults reaches between 2 and 4 per cent, and an increase by 2.3 times is expected [52].

Age is an independent risk factor for the occurrence of this arrhythmia. In 2010, the population with atrial fibrillation was estimated at 5.6 million in Western Europe. Based on the analyses, it is estimated that in 2060 this population may reach 13.8 million people. Patients over 80 years of age will constitute the majority of this group $(65.2 \%)[53,54]$.

The connection of atrial fibrillation and increased mortality is well documented. Allcause mortality risk is two times higher in women and 1.5 higher in men with atrial fibrillation [55-57]. Similarly, the increased mortality risk is observed in patients with other cardiovascular system diseases. Atrial fibrillation significantly increases the risk of sudden cardiac death both in the general population and in patients with coronary artery disease, heart failure and patients with CIED [58].

\subsection{Limitations}

The present research has its limitations, including its single-center nature and the lack of a broader clinical profile for all patients (e.g., pharmacotherapy data). Another limitation of the present work is that laboratory parameters were not included, which might, to some extent, allow for predictions of the outcome. Nonetheless, all patients were assessed according to nonheart-related comorbidities, which form a certain equivalent to positive or negative laboratory results. Another limitation of current analysis is insufficient data on concomitant chronic illness, especially in frail elderly and cardiological patients that frequently require hospitalization in real life. This issue is currently under consideration, especially in chronic heart failure and the COVID-19 era. This aspect needs further investigation analysis.

\section{Conclusions}

Despite the application of modern treatment methods, such as the use of CIED, patients required further specialist care after the performed procedures. A significant number had to be re-admitted to hospital for cardiological reasons (most frequently heart failure, atrial fibrillation, and coronary artery disease). The complexity of the clinical picture was also the reason for the need for consultations in outpatient specialist clinics. On the basis of the analysis performed, it was found that diseases requiring specialist nephrological, pulmonological, and orthopedic treatment had the greatest impact on the need for rehospitalization for the above reasons. Effective organization of care after CIED procedures may be important in reducing the most expensive component of this care, that is, inpatient treatment.

Author Contributions: Conceptualization, R.Z., M.G. and W.D.; methodology, R.Z., M.G. and A.M. (Anna Milewska); software, R.Z.; validation, R.Z. and M.G.; formal analysis, R.Z., M.G., A.M. (Anna Milewska) and A.M. (Anastasius Moumtzoglou); investigation, R.Z.; resources, R.Z.; data curation, R.Z. and A.M. (Anna Milewska); writing-original draft preparation, R.Z.; writing-review and editing, R.Z. and M.G.; supervision, M.G. and W.D.; project administration, R.Z. All authors have read and agreed to the published version of the manuscript.

Funding: This research received no external funding. 
Institutional Review Board Statement: Ethical evaluation and approval for this study were waived because of the retrospective nature of the registry created on the basis of standard, archival medical records not requiring active or passive participation of patients or performing additional procedures. It was reported to the Bioethics Committee at the Medical University of Warsaw.

Informed Consent Statement: Patient consent was waived due to the retrospective nature of the registry created on the basis of standard, archival medical records not requiring active or passive participation of patients or performing additional procedures.

Data Availability Statement: The data presented in this study are available upon reasonable request from the corresponding author.

Acknowledgments: This research is conducted within the EU-financed Inter Doktor Men project (POWR.03.02.00-00-I027/16).

Conflicts of Interest: The authors declare no conflict of interest.

\section{References}

1. Glikson, M.; Nielsen, J.C.; Kronborg, M.B.; Michowitz, Y.; Auricchio, A.; Barbash, I.M.; Barrabés, J.A.; Boriani, G.; Braun-schweig, F.; Brignole, M.; et al. ESC Guidelines on cardiac pacing and cardiac resynchronization therapy. Eur. Heart J. 2021, 42, 3427-3520. [CrossRef]

2. McDonagh, T.A.; Metra, M.; Adamo, M.; Gardner, M.S.; Baumbach, A.; Böhm, M.; Burri, H.; Butler, J.; Čelutkienė, J.; Chioncel, O.; et al. ESC Guidelines for the diagnosis and treatment of acute and chronic heart failure. Eur. Heart J. 2021, 42, 3599-3726. [CrossRef] [PubMed]

3. Priori, S.G.; Blomström-Lundqvist, C.; Mazzanti, M.; Blom, N.; Borggrefe, M.; Camm, J.; Elliott, P.M.; Fitzsimons, D.; Hatala, R.; Hindricks, G.; et al. ESC Guidelines for the management of patients with ventricular arrhythmias and the prevention of sudden cardiac death: The Task Force for the Management of Patients with Ventricular Arrhythmias and the Prevention of Sudden Cardiac Death of the European Society of Cardiology (ESC). Endorsed by: Association for European Paediatric and Congenital Cardiology (AEPC). Eur. Heart J. 2015, 36, 2793-2867.

4. Al-Khatib, S.M.; Stevenson, W.G.; Ackerman, M.J.; Bryant, W.J.; Callans, D.J.; Curtis, A.B.; Deal, B.J.; Dickfeld, T.; Field, M.E.; Fonarow, G.C.; et al. 2017 AHA/ACC/HRS Guideline for Management of Patients With Ventricular Arrhythmias and the Prevention of Sudden Cardiac Death: A Report of the American College of Cardiology/American Heart Associa-tion Task Force on Clinical Practice Guidelines and the Heart Rhythm Society. J. Am. Coll. Cardiol. 2018, 72, e91-e220.

5. Załuska, R.; Milewska, A.; Moumtzoglou, A.; Grabowski, M.; Drygas, W. Long-Term, Single-Centre Observation of Patients with Cardiac Implantable Electronic Devices. Medicina 2021, 57, 1357. [CrossRef]

6. AlTurki, A.; Marafi, M.; Russo, V.; Proietti, R.P.; Essebag, V. Subclinical Atrial Fibrillation and Risk of Stroke: Past, Present and Future. Medicina 2019, 55, 611. [CrossRef]

7. Poland: Country Health Profile 2019. Available online: https:/ /www.oecd.org/health/poland-country-health-profile-2019-297 e4b92-en.htm. (accessed on 1 October 2021).

8. Kaźmierczak, J.; Zielonka, J.; Rzeuski, R.; Peregud-Pogorzelska, M.; Goracy, J.; Biernawska, J.; Sulikowski, T.; Kornalcewicz-Jach, Z. Hospital readmission in patients with implantable cardioverter-defibrillators. Cardiol. Pol. 2006, 64, 684-691.

9. Higgins, A.Y.; Bjerre, J.; Parzynski, C.S.; Minges, K.E.; Ahmad, T.; Desai, N.R.; Enriquez, A.; Spatz, E.S.; Friedman, D.J.; Curtis, J.P.; et al. Comparison of Mortality and Readmission in Non-Ischemic Versus Ischemic Cardiomyopathy after Implantable Cardioverter-Defibrillator Implantation. Am. J. Cardiol. 2020, 133, 116-125. [CrossRef]

10. Alla, F.; Zannad, F.; Filippatos, G. Epidemiology of acute heart failure syndromes. Heart Fail. Rev. 2007, 12, 91-95. [CrossRef] [PubMed]

11. Nichols, G.A.; Reynolds, K.; Kimes, T.M.; Rosalets, A.G.; Chan, W.W. Comparison of risk of re-hospitalization, all-cause mortality, and medical care resource utilization in patients with heart failure and preserved versus reduced ejection fraction. Am. J. Cardiol. 2015, 116, 1088-1092. [CrossRef] [PubMed]

12. Shah, K.S.; Xu, H.; Matsouaka, R. Heart failure with preserved, borderline, and reduced ejection fraction: 5-year outcomes. J. Am. Coll. Cardiol. 2017, 70, 2476-2486. [CrossRef]

13. Umehara, T.; Katayama, N.; Tsunematsu, M. Factors affecting hospital readmission heart failure patients in Japan: A mul-ticenter retrospective cohort study. Heart Vessels 2020, 35, 367-375. [CrossRef]

14. Heart Failure Policy and Practice in Poland. Available online: www.hfpolicynetwork.org/wp-content/uploads/Heart-failurepolicy-and-practice-in-Europe-Poland.pdf (accessed on 1 October 2021).

15. Organisation for Economic Co-operation and Development. Health at a Glance 2015; OECD Indicators; OECD Publishing: Paris, France, 2015.

16. McAlister, F.A.; Stewart, S.; Ferrua, S. Multidisciplinary Strategies for the management of heart failure patients at high risk for admission: A systematic review of randomized trials. J. Am. Coll. Cardiol. 2004, 44, 810-819. [PubMed]

17. Freeman, J.V.; Wang, Y.; Akar, J.; Detsai, A.N.; Krumholz, H. National trends in atrial fibrillation hospitalization, readmission, and mortality for Medicare beneficiaries, 1999-2013. Circulation 2017, 135, 1227-1239. [CrossRef] [PubMed] 
18. Patel, N.J.; Atti, V.; Mitrani, R.D.; Vilet s-Gonzalez, J.F.; Goldberger, J.J. Global rising trends of atrial fibrillation: A major public health concern. Heart 2018, 104, 1989-1990. [CrossRef] [PubMed]

19. Johnson, B.H.; Smoyer-Tomic, K.E.; Siu, K.; Walker, D.R.; Sander, S.; Huse, D.; Smith, D.M.; Song, X.; Amin, A. Readmission among hospitalized patients with nonvalvular atrial fibrillation. Am. J. Health Syst. Pharm. 2013, 70, 414-422. [CrossRef]

20. Violi, F.; Soliman, E.Z.; Pignatelli, P.; Pastori, D. Atrial Fibrillation and Myocardial Infarction: A Systematic Review and Appraisal of Pathophysiologic Mechanisms. J. Am. Heart Assoc. 2016, 5, e003347. [CrossRef]

21. Baumeister, S.E.; Böger, C.A.; Krämer, B.K.; Döring, A.; Eheberg, D.; Fischer, B.; John, J.; Koenig, W.; Meisinger, C. Effect of chronic kidney disease and comorbid conditions on health care costs: A 10-year observational study in a general population. Am. J. Nephrol. 2010, 31, 222-229. [CrossRef]

22. Honeycutt, A.A.; Segel, J.E.; Zhuo, X.; Hoerger, T.J.; Imai, K.; Williams, D. Medical costs of CKD in the Medicare population. J. Am. Soc. Nephrol. 2013, 24, 1478-1483. [CrossRef]

23. Kent, S.; Schlackow, I.; Lozano-Kühne, J. SHARP Collaborative Group: What is the impact of chronic kidney disease stage and cardiovascular disease on the annual cost of hospital care in moderate-to-severe kidney disease? BMC Nephrol. 2015, 16, 65. [CrossRef]

24. Smith, D.H.; Gullion, C.M.; Nichols, G. Cost of medical care for chronic kidney disease and comorbidity among en-rollees in a large HMO population. J. Am. Soc. Nephrol. 2004, 15, 1300-1306. [CrossRef] [PubMed]

25. Ronksley, P.; Hemmelgarn, B.R.; Manns, B.J.; Wick, J.; James, M.T.; Ravani, P.; Quinn, R.R.; Scott-Douglas, N.; Lewanczuk, R.; Tonelli, M. Potentially Preventable Hospitalization among Patients with CKD and High Inpatient Use. Clin. J. Am. Soc. Nephrol. 2016, 11, 2022-2031. [CrossRef]

26. Reschovsky, J.D.; Hadley, J.; Saiontz-Martinez, C.B. Following the money: Factors associated with the cost of treating high-cost Medicare beneficiaries. Health Serv. Res. 2011, 46, 997-1021. [CrossRef] [PubMed]

27. Stange, K.C. The problem of fragmentation and the need for integrative solutions. Ann. Fam. Med. 2009, 7, 100-103. [CrossRef]

28. Epstein, K.; Juarez, E.; Epstein, A.; Loya, K.; Singer, A. The impact of fragmentation of hospitalist care on length of stay. J. Hosp. Med. 2010, 5, 335-338. [CrossRef] [PubMed]

29. Tsai, T.C.; Orav, E.J.; Jha, A.K. Care fragmentation in the post discharge period: Surgical readmissions, distance of travel, and postoperative mortality. JAMA Surg. 2015, 150, 59-64. [CrossRef]

30. Frandsen, B.R.; Joynt, K.E.; Rebitzer, J.B. Care fragmentation, quality, and costs among chronically ill patients. Am. J. Manag. Care 2015, 21, 355-362.

31. Schrag, D.; Xu, F.; Hanger, M.; Elkin, E.; Bickell, N.A.; Bach, P.B. Fragmentation of care for frequently hospitalized urban residents. Med. Care 2006, 44, 560-567. [CrossRef]

32. Khanam, M.A.; Streatfield, P.K.; Kabir, Z.N. Prevalence and patterns of multimorbidity among elderly people in rural Bangladesh: A cross-sectional study. J. Health Popul. Nutr. 2011, 29, 406-414. [CrossRef]

33. Machlin, S.; Cohen, J.; Beauregard, K. Health Care Expenses for Adults with Chronic Conditions; Statistical Brief 2008 \# 203; Agency for Health Care Research and Quality: Rockville, MD, USA, 2005. Available online: http://www.meps.ahrq.gov/mepsweb/ data_files/publications/st203/stat203 (accessed on 1 October 2021).

34. Kailasam, M.; Guo, W.; Hsann, Y.M. Prevalence of care fragmentation among outpatients attending specialist clinics in a regional hospital in Singapore: A cross-sectional study. BMJ Open 2019, 9, e022965. [CrossRef]

35. Rutten, F.H.; Cramer, M.J.; Lammers, J.W.; Grobbee, D.E.; Hoes, A.W. Heart failure and chronic obstructive pulmonary disease: An ignored combination? Eur J. Heart Fail. 2006, 8, 706-711. [CrossRef] [PubMed]

36. Minasian, A.G.; van den Elshout, F.J.J.; Dekhuijzen, R.P.N.; Willems, F.F.; Bergh, P.J.V.D.; Heijdra, Y.F. COPD in chronic heart failure: Less common than previously thought? Heart Lung. 2013, 42, 365-371. [CrossRef]

37. Apostolovic, S.; Jankovic-Tomasevic, R.; Salinger-Martinovic, S. Frequency and significance of unrecognized chronic obstructive pulmonary disease in elderly patients with stable heart failure. Aging Clin. Exp. Res. 2011, 23, 337-342. [CrossRef] [PubMed]

38. Sharif, R.; Parekh, T.; Kuo, Y.F. Predictors of early readmission among patients hospitalized with chronic obstructive pulmonary disease. Chest 2014, 145, 420A. [CrossRef]

39. Halbert, R.J.; Natoli, J.L.; Gano, A.; Badamgarav, E.; Buist, A.S.; Mannino, D. Global burden of COPD: Systematic review and meta-analysis. Eur. Respir. J. 2006, 28, 523-532. [CrossRef]

40. Sullivan, S.D.; Ramsey, S.D.; Lee, T.A. The economic burden of COPD. Chest 2000, 117, 5S-9S. [CrossRef]

41. Curkendall, S.M.; DeLuise, C.; Jones, J.K.; Lanes, S.; Stang, M.R.; Goehring, E.; She, D. Cardiovascular disease in patients with chronic obstructive pulmonary disease, Saskatchewan Canada cardiovascular disease in COPD patients. Ann. Epidemiol. 2006, 16, 63-70. [CrossRef] [PubMed]

42. Kaszuba, E.; Odjerg, H.; Råstam, L. Heart failure and levels of other comorbidities in patients with chronic obstruc-tive pulmonary disease in a Swedish population: A register-based study. BMC Res. Notes 2016, 9, 215. [CrossRef] [PubMed]

43. Pong, R.W.; DesMeules, M.; Heng, D.; Lagacé, C.; Guernsey, J.R.; Kazanjian, A.; Manuel, D.; Pitblado, J.R.; Bollman, R.; Koren, I.; et al. Patterns of health services utilization in rural Canada. Chronic Dis. Inj. Can. 2011, 31, 1-36. [CrossRef]

44. Lamblin, N.; Ninni, S.; Tricot, O.; Meurice, T.; Lemesle, G.; Bauters, C. Secondary prevention and outcomes in outpatients with coronary artery disease, atrial fibrillation or heart failure: A focus on disease overlap. Open Heart 2020, 7, e001165. [CrossRef]

45. Conrad, N.; Judge, A.; Tran, J.; Mohseni, H.; Hedgecott, D.; Crespillo, A.C.; Allison, M.; Hemingway, H.; Cleland, J.G.; McMurray, J.J.V.; et al. Temporal trends and patterns in heart failure incidence: A population-based study of 4 million individuals. Lancet 2018, 391, 572-580. [CrossRef] 
46. Savarese, G.; Lund, L.H. Global Public Health Burden of Heart Failure. Card Fail. Rev. 2017, 3, 7-11. [CrossRef]

47. Van Riet, E.E.S.; Hoes, A.W.; Wagenaar, K.P.; Limburg, A.; Landman, M.A.J.; Rutten, F.H. Epidemiology of heart failure: The prevalence of heart failure and ventricular dysfunction in older adults over time. A systematic review. Eur. J. Heart Fail. 2016, 18, $242-252$. [CrossRef]

48. Benjamin, E.J.; Virani, S.S.; Callaway, C.W.; Chamberlain, A.M.; Chang, A.R.; Cheng, S.; Chiuve, S.E.; Cushman, M.; Delling, F.N.; Deo, R.; et al. American Heart Association Council on Epidemiology and Prevention Statistics Committee and Stroke Statistics Subcommittee. Heart disease and stroke statistics_2018 update: A report from the American Heart Association. Circulation 2018, 137, e67-e492. [CrossRef] [PubMed]

49. Tsao, C.W.; Lyass, A.; Enserro, D.; Larson, M.G.; Ho, J.E.; Kizer, J.R.; Gottdiener, J.S.; Psaty, B.M.; Vasan, R.S. Temporal trends in the incidence of and mortality associated with heart failure with preserved and reduced ejection fraction. JACC Heart Fail. 2018, 6, 678-685. [CrossRef]

50. Madhavan, M.V.; Gersh, B.J.; Alexander, K.P.; Granger, C.B.; Stone, G.W. Coronary Artery Disease in Patients $\geq 80$ Years of Age. J. Am. Coll. Cardiol. 2018, 71, 2015-2040. [CrossRef]

51. Sorbets, E.; Kim, K.M.; Elbez, Y.; Danchin, N.; Dorian, P.; Ferrari, R.; Ford, J.; Greenlaw, N.; Kalra, P.R.; Parma, Z.; et al. CLARIFY investigators. Long-term outcomes of chronic coronary syndrome worldwide: Insights from the international CLARIFY registry. Eur. Heart J. 2020, 41, 347-356. [CrossRef]

52. Benjamin, E.J.; Muntner, P.; Alonso, A.; Bittencourt, M.S.; Callaway, C.W.; Carson, A.P.; Chamberlain, A.M.; Chang, A.R.; Cheng, S.; Das, S.R.; et al. American Heart Association Council on Epidemiology and Prevention Statistics Committee and Stroke Statistics Subcommittee. Heart disease and stroke statistics 2019 update: A report from the American Heart Association. Circulation 2019, 139, e56-e528. [CrossRef] [PubMed]

53. Krijthe, B.P.; Kunst, A.; Benjamin, E.J.; Lip, G.Y.; Franco, O.H.; Hofman, A.; Witteman, J.C.; Stricker, B.H.; Heeringa, J. Projections on the number of individuals with atrial fibril lation in the European Union, from 2000 to 2060. Eur. Heart J. 2013, 34, $2746-2751$. [CrossRef] [PubMed]

54. Polidori, M.C.; Alves, M.; Bahat, G.; Boureau, A.S.; Ozkok, S.; Pfister, R.; Pilotto, A.; Veronese, N.; Bo, M. Special Interest Group "Cardiovascular Diseases" of the EuGMS. Atrial fibrillation: A geriatric perspective on the 2020 ESC guidelines. Eur. Geriatr. Med. 2021, 2, 1-14.

55. Benjamin, E.J.; Wolf, P.A.; D'Agostino, R.B.; Silbershatz, H.; Kannel, W.B.; Levy, D. Impact of atrial fibrillation on the risk of death: The Framingham Heart Study. Circulation 1998, 98, 946-952. [CrossRef] [PubMed]

56. Stewart, S.; Hart, C.L.; Hole, D.J.; McMurray, J.J. A population-based study of the long term risks associated with atrial fibrillation: 20-year follow-up of the Renfrew/Paisley study. Am. J. Med. 2002, 113, 359-364. [CrossRef]

57. Andersson, T.; Magnuson, A.; Bryngelsson, I.L.; Frobert, O.; Henriksson, K.M.; Edvardsson, N.; Poci, D. All-cause mortality in 272,186 patients hospitalized with incident atrial fibrillation 1995-2008: A Swedish nationwide long-term case control study. Eur. Heart J. 2013, 34, 1061-1067. [CrossRef] [PubMed]

58. Rattanawong, P.; Upala, S.; Riangwiwat, T.; Jaruvongvanich, V.; Sanguankeo, A.; Vutthikraivit, W.; Chung, E.H. Atrial fibrillation is associated with sudden cardiac death: A systematic review and meta-analysis. J. Interv. Card Electrophysiol. 2018, 51, 91-104. [CrossRef] [PubMed] 